PEAT

\section{Pennsylvanian Deposits}

from a Correspondent

WETLAND ecosystems are particularly prone to human interference. Either they are drained for agriculture or they are exploited for peat, but rarely are they left untouched. The reason for this is probably that it is difficult to justify mire conservation except in terms of the intrinsic scientific interest of the habitat, which appeals only to a relatively small minority of the population. The interest of these habitats lies both in their distinctive wildlife and also in that they build up a record of their own development in the peat which they form. Peat is an accumulation of the remains of dead vegetation which once grew upon the surface of the mire. Waterlogged, anaerobic conditions discourage microbial activity so that decay processes become impaired. Such remains are often recognizable and document the vegetational succession on the site. Furthermore, the peat contains pollen which may have travelled considerable distances in the air before being deposited on the mire surface and from this can be reconstructed the vegetational history of much larger areas surrounding the mire. Such information can be valuable in the study of climatic changes in a region.

Peat has long been valued as an energy reserve, a fossil fuel of recent origin. But in recent times its value as a horticultural commodity has risen very considerably, a value which derives from certain of its physical properties. In the first place it is a source of organic matter which, when added to a well aerated soil, acts as an energy source for soil microbes and thus improves soil structure. The water holding capacity of peat is very high, its value depending upon the vegetation from which it was formed, for example, Sphagnum moss peat can hold 800 per cent of its dry weight in water, and for sedge peat the figure is about 400 per cent. Peat also has properties of nutrient retention which make it valuable when added with fertilizers to soil. This horticultural demand for peat has placed a new stress on the world's harassed wetlands.

A recent bulletin of the United States Geological Survey (C. C. Cameron, Bulletin 1317-A; 1970) is devoted to the peat deposits of the Appalachian Mountain region of north-east Pennsylvania. The author calculates that the resources of this 900 square mile area are more than 13 million short tons of air dried peat. This estimate is based on a study of ninety-five peat deposits most of which are less than 100 acres in area and less than 16 feet deep. In spite of the small size of these resources (between 10,000 and 100,000 tons each), the proximity of the Atlantic seaboard and metropolitan markets for peat products makes their exploitation an economic possibility. In 1966 the United States imported peat to the value of $\$ 11 \frac{1}{2}$ million. With a demand of this size it is understandable that the Department of the Interior should seek a home supply of peat. If economic needs demand the exploitation of an area such as north-east Pennsylvania, this should be accompanied by the conservation of selected sites representative of the wide range of mire types found in that area. In this way the irretrievable loss of valuable ecological information can be avoided.

\section{PLANT GROWTH}

\section{Izmir Instilute}

from a Correspondent

"Never has so much been said by so many on a subject about which we know so little." This remark, which was made at the 1955 Wye College conference on plant growth regulation, is perhaps as true today as it was then. The NATO Advanced Summer Institute on the same subject, which was held at Izmir in Turkey from September 20 to October 1 , highlighted the complexity of the interactions between the classical auxins and the gibberellins, cytokinins, abscisic acid and ethylene. It also stressed the need for "translating" results obtained on segments of plants to whole plants.

The organizers arranged for a general review to precede the more detailed accounts of research on specific topics. This met one of the objectives of the NATO institute; that is, to provide students with a general survey of the field while at the same time providing a forum for research workers to present original work. Dr I. D. J. Phillips (University of Exeter) opened the proceedings with a review of the principles of promotion and inhibition of growth in plants. This was followed by an original paper by Professor E. C. Cocking (University of Nottingham) on specific discussion of growth in isolated protoplasts. Other contributions from the United Kingdom included reviews on the gibberellins (Dr J. Macmillan, University of Bristol), some recent studies on gibberellin-like substances in higher plants (Dr J. L. Stoddart, Welsh Plant Breeding Station) and growth regula-

\title{
How the Molecules of Collagen are Assembled
}

Nexr Wednesday's Nature New Biology will see the publication of the third article in the past few months on a longstanding problem in molecular biology; how the molecules of collagen are assembled in three dimensions to produce functional connective tissue. Each approach starts with different data and it is interesting that they all point to the same solution - a five-fold microfibril.

The latest study comes straight to the point that any answer must finally explain. How is the molecular packing related to the molecular structure? Segrest and Cunningham start with the tropocollagen molecule, a three-strand rope formed by supercoiling two identical helices termed $\alpha_{1}$ and $\alpha_{2}$. They speculate that the primordial collagen may have contained three identical chains of general structure (gly-pro-X)where $\mathrm{X}$ is apolar. Fibril formation would likely take place by more or less random parallel aggregation of such molecules. They then suppose that a mutation in the nucleic acid led to a charged side-chain at the same level in all three $\alpha$ chains, followed by a second mutation which resulted in the appearance of a second charge side-chain, complementary to the first and separated by a suitable distance along the molecule. If the relative positions of the two new complementary groups are correct, fibril growth may proceed by lateral accretion of staggered molecules.
In addition to appropriate position along the length of the molecule, several factors are involved in the correct relationship of mutations for fibril growth. When parallel cylinders are packed they touch along edges of contact. For helices, points which lie along such an edge must be separated axially by integrals of the pitch of the helices. Thus mutations can only occur along these edges for formation of a regular fibril. Segrest and Cunningham list the types of packing which could result from various mutation positions. One of these is a hexagonal array; another is an extended pleated sheet. The third is the five-fold microfibril suggested independently on other grounds. The two identical $\alpha_{1}$ chains in the tropocollagen molecule are related by an aximuthal rotation of $108^{\circ}$, so that the existence of contact edge on one chain automatically generates an identical edge $108^{\circ}$ round from the first. If complementarity of these edges can be obtained by an axial stagger, then a second molecule would add to the first at an angle of $108^{\circ}$ which is the internal angle of a pentagon.

Model building has its limitations. Without further information it is frequently only able to indicate possible structures. It is gratifying to see how the microfibril suggested by X-ray diffraction and electron microscopy arises readily from the structure of the component molecules. 